NBER WORKING PAPER SERIES

\title{
THE ROLE OF CHILDCARE CHALLENGES IN THE US JOBS MARKET RECOVERY DURING THE COVID-19 PANDEMIC
}

\author{
Jason Furman \\ Melissa Schettini Kearney \\ Wilson Powell \\ Working Paper 28934 \\ http://www.nber.org/papers/w28934 \\ NATIONAL BUREAU OF ECONOMIC RESEARCH \\ 1050 Massachusetts Avenue \\ Cambridge, MA 02138 \\ June 2021
}

An earlier, shorter version of this paper was posted on May 17, 2021 as a blog post on the websites of the Peterson Institute for International Economics (PIIE) and Aspen Economic Strategy Group (AESG). The authors thank Lawrence Katz, Jed Kolko, and David Wilcox for helpful comments on an earlier draft and Madona Devasahayam for editing suggestions. The views expressed herein are those of the authors and do not necessarily reflect the views of the National Bureau of Economic Research.

NBER working papers are circulated for discussion and comment purposes. They have not been peer-reviewed or been subject to the review by the NBER Board of Directors that accompanies official NBER publications.

(C) 2021 by Jason Furman, Melissa Schettini Kearney, and Wilson Powell. All rights reserved. Short sections of text, not to exceed two paragraphs, may be quoted without explicit permission provided that full credit, including $(\odot$ notice, is given to the source. 
The Role of Childcare Challenges in the US Jobs Market Recovery During the COVID-19

Pandemic

Jason Furman, Melissa Schettini Kearney, and Wilson Powell

NBER Working Paper No. 28934

June 2021

JEL No. J01,J18,J21

\section{$\underline{\text { ABSTRACT }}$}

We examine how much of the overall decline in employment between the beginning of 2020 and 2021 can be explained by excess job loss among parents of young children, and mothers specifically. Using data from the Current Population Survey (CPS), we confirm that, in general, mothers with young children have experienced a larger decline in employment, as compared (unconditionally) with other adults, including fathers. This excess job loss is driven by mothers without a four-year college (bachelor's) degree. The main point of the paper is to build off this observation and examine how much of the aggregate employment deficit in early 2021 can be explained by parent-specific issues, such as childcare struggles. To examine this question, we construct counterfactual employment rates and labor force participation rates that assign to mothers of young children the percent change in employment and labor force participation rates experienced by comparable women without young children. We consider multiple definition, sample, and counterfactual specification alternatives. Our analysis yields robust evidence that differential job loss among mothers of young children accounts for a negligible share of the ongoing aggregate employment deficit. The result is even stronger (and flips signs) if we consider all parents, since fathers with young children experienced less job loss than other men. The practical implication of these findings is that nearly all of the aggregate ongoing employment deficit is explained by factors that affect workers more broadly, as opposed to challenges specific to working parents.

Jason Furman

Harvard University

79 John F. Kennedy St. Box 82

Cambridge, MA 02138

jason_furman@harvard.edu

Melissa Schettini Kearney

Department of Economics

University of Maryland

3105 Tydings Hall

College Park, MD 20742

and NBER

kearney@econ.umd.edu
Wilson Powell

Harvard Kennedy School

wilson_powell@hks.harvard.edu

Supplementary data files are available at http://www.nber.org/data-appendix/w28934 


\section{Introduction}

The US economy lost a net of around 8 million jobs between February 2020 and April

2021. People not actively seeking employment (inadequate labor supply) appeared to have played a major role in the job losses over this period, as evidenced by factors including record job openings, the largest wage increases in decades, and other signs of a tighter labor market than would generally be expected given the still low levels of employment. ${ }^{1}$ Why has labor supply been slow to return? There are many candidate explanations, including the ongoing worry among some adults about getting COVID-19 if they return to the workplace, the increased availability and generosity of unemployment insurance benefits, and challenges for working parents associated with closed schools and inadequate childcare, among others. Diagnosing the sources of ongoing weak labor supply is important to inform the types of policies that are needed now to speed the labor market recovery.

In this analysis, we quantify how much of the overall decline in employment can be explained by excess job loss among parents of young children, and mothers specifically. This exercise sheds light on the potential effect of childcare challenges on the labor market. ${ }^{2}$ We construct counterfactual employment rates, or employment-to-population ratios, as well as labor force participation rates that assign to parents with young children the percent change in employment and labor force participation rates experienced by comparable people without young children. The results of this exercise imply that differential job loss among mothers accounts for a negligible share of aggregate job loss between January and February of 2020 and 2021.

\footnotetext{
${ }^{1}$ See, for instance, Strain (2021), Furman and Powell (2021), and Ip (2021).

${ }^{2}$ Many observers worried that ongoing closures of school and childcare facilities would hamper the ability of parents to return to work. A working paper by Dingel, Patterson, and Vavra (2020) documented that according to data from the 2018 American Community Survey, 32 percent of that workforce, or 50 million Americans, has someone in their household who is under 14 and would thus have to consider childcare obligations when returning to work.
} 
Looking at all parents (mothers and fathers combined) strengthens the qualitative finding because fathers actually had relatively less job loss than otherwise similar men. The results suggest that despite the widespread challenges that parents—mothers in particular—have faced from ongoing school and daycare closures, excess employment declines among mothers of young children were not a quantitatively important driver of continuing low employment levels through the beginning of 2021.

The employment rates of parents of young children (any own child under 13 in the household, including adopted children and stepchildren, in our baseline definition) have declined by 5.0 percent, as compared with 6.1 percent among people who are not parents of young children. Mothers have experienced larger declines in employment than fathers: 6.3 percent versus 3.7 percent. ${ }^{3}$ Mothers without a four-year college degree have experienced the largest declines: 8.6 percent. In fact, fathers of young children have experienced smaller declines in employment than men without young children: 3.7 percent versus 6.1 percent. Though descriptively important, these comparisons do not necessarily imply that parents have experienced differential job loss as compared with other adults (those aged 16 and older) with otherwise similar demographic profiles, say, by age and education level. Our counterfactual analysis accounts for basic demographic confounders.

Our baseline counterfactual model implies that excess job loss among mothers of young children can account for about 1 percent of the aggregate decline in employment and about 3 percent of the aggregate decline in labor force participation between January/February 2020 and January/February 2021. This baseline model assigns mothers of young children the employment

\footnotetext{
3 The divergent employment experiences between mothers and fathers during the pandemic have been documented in detail by others; for instance, see Heggeness (2020) and Lofton, Petrosky-Nadeau, and Seitelman (2021).
} 
rates of demographically comparable women based only on age category and four-year college degree status.

Two features of the data explain this small aggregate share. First, comparing mothers with young children to other women with similar age and education profiles largely eliminates the finding of excess job loss observed with unconditional comparisons-although we are not claiming that the results establish a precise estimate of zero relationship and in fact the majority of our specifications show some differential employment reductions for mothers of small children. Second, mothers with young children comprise only 12 percent of the overall workforce (measured in early 2020), so even if this group did experience excess job loss as compared with otherwise similar women, that would explain only a small share of the overall decline. The estimated share of the overall decline in employment that can be explained by challenges particular to parents of young children, including fathers, is negative, on account of the relatively smaller decline in employment among fathers as compared with otherwise demographically similar men.

Though outside the scope of this analysis, school closings and ongoing childcare challenges have undoubtedly been a tremendous source of stress for many parents during the pandemic. ${ }^{4}$ They are also likely to have lasting, negative impacts on the learning and social development of children. ${ }^{5}$ In this analysis, however, our focus is on one specific, empirical question: How much of the aggregate employment decline observed in the early part of 2021 can be attributed to childcare and other issues unique to mothers (or parents) of young children? The results of our counterfactual analysis suggest that parents of young children have experienced declines in employment and labor force participation over the year that are similar in magnitude

\footnotetext{
${ }^{4}$ See, for instance, Lee, Ward, Chang, and Downing (2021).

${ }^{5}$ See, for instance, Dorn, Hancock, Sarakatsannis, and Viruleg (2020) and Peterson (2020).
} 
to other demographically similar adults. This suggests that the slow employment recovery likely reflects challenges affecting workers more broadly.

\section{Employment declines among parents}

Women with young children have experienced the greatest rate of job loss over the past year, which is descriptively consistent with the hypothesis that school closures and childcare struggles have lowered women's work during the pandemic. Employment counts from the Current Population Survey in January and February of 2020 and 2021 confirm that between early 2020 and early 2021, employment rates fell more for women with young children than for all other women. Among all women, the employment rate fell by 6.3 percent (4.4 percentage points) for those with at least one child under 13, as compared with 6.1 percent (3.2 percentage points) for those without a child under 13 .

The pattern is reversed among men, with larger declines among men without young children than among men with young children. The employment rate fell by 3.7 percent (3.4 percentage points) for men with at least one child under 13, as compared with a decline of 6.1 percent (3.7 percentage points) for men without a child under 13. Though explaining this difference by gender is beyond the scope of this analysis, one possible explanation is the substitutability of labor supply between parents. ${ }^{6}$

The gap in employment declines between mothers with young children and other women is driven by women without a bachelor's degree. Figure 1 shows changes in the employment rates for individuals with any child under 13 and those without, separately for men and women

\footnotetext{
${ }^{6}$ For both men and women, these reported comparisons are unadjusted, meaning that they could reflect a causal effect of child-related struggles, or either observable or unobservable differences between men and women with and without young children. Our counterfactual analysis reported below accounts for various observable differences between men and women with and without young children.
} 
with and without a bachelor's degree. As can be seen in the figure, among women with a bachelor's degree, mothers of young children experienced a smaller proportional decline in employment than women without a young child: 3.9 percent (3.0 percentage points) as compared with 4.4 percent (3.0 percentage points). But, among women without a bachelor's degree, women with young children experienced a larger decline in employment: 8.6 percent (5.4 percentage points), as compared with 7.9 percent (3.6 percentage points) for women without young children. Figure 2 shows these same changes in percentage point terms. Combined, mothers of young children were 12 percent of overall employment in January and February 2020, while fathers of young children were an additional 13 percent of employment.

These comparisons are noteworthy and descriptively interesting, but they are not necessarily indicative of an effect of childcare struggles, school closures, or other factors associated with parenting on employment declines, even for mothers without a bachelor's degree. The reason is because women with and without young children differ on other dimensions that are related to employment outcomes, such as age, marital status, income, race and ethnicity, and industry. We next turn to a counterfactual analysis to estimate how much of the decline in employment—both overall and for mothers in particular—is attributable to having a young child in the household (and the associated challenges), adjusting for a range of factors.

\section{Counterfactual analysis: What if the pandemic labor market experience of parents with young children was like that of otherwise similar adults without young children?}

The heart of our analysis is a counterfactual: What would have happened to aggregate employment rates if parents with young children experienced the same rate of employment decline as adults without young children? This provides a reasonable estimate of the potential 
role of factors that affect families with young children, especially school closures and lack of childcare.

The motivation for this exercise is the observation that the fact that millions of mothers of young children have lost jobs or left the labor force is not, by itself, evidence that childcare, school closings, or other child-related reasons are to blame. Hypothetically, if employment rates or labor force participation rates fell by the same proportion for similar people with and without young children, the primary causes of the decline are likely to be factors other than childcare challenges or school closures. In such a case, the source of the decline in employment among parents with young children would likely be something that was affecting everyone in a similar manner, such as workplaces being closed, jobs being undesirably unsafe, or unemployment insurance benefits being more generous and available.

A very simple, naïve counterfactual exercise is to ask what would have happened to the overall employment rate if the employment of mothers with young children changed in the same way it did for women without young children. That is, what if women with young children experienced only a 6.1 percent decline in employment, instead of the 6.3 percent decline they actually did? Given that mothers with young children were 12 percent of total employment at the beginning of 2020, this would have resulted in the aggregate employment rate falling by 3.58 percentage points, 0.02 percentage point less than the 3.60 percentage points it actually did. (If we apply this counterfactual calculation to both mothers and fathers with young children, the decline in employment would have been even larger than observed.)

The naïve counterfactual ignores the myriad ways that people with and without young children are different, including their age and education profiles and the industries they work in. For instance, mothers with a child under 13 tend to be younger than women without a child 
under 13; the average age in our data is 37 versus 50 years. Mothers with a child under 13 are also more likely to hold a four-year college degree than women without a child under 13: 41 percent versus 33 percent. The distribution of industries is also a bit different between these two groups. It is thus the case that differences that might look like a disparate impact of having young children during the pandemic might actually reflect different rates of job loss for young and older workers, more or less educated workers, or for workers in certain industries versus others.

\section{A. Main Results}

Our baseline counterfactual accounts for some basic demographic differences between adults with and without a child under 13 . Specifically, we collapse the data into cells defined by sex, four age groups, and whether someone has a bachelor's degree. For each sex-age-education cell, we calculate what employment would have been if parents with a child under 13 experienced the same percent change in employment as adults in the same sex-age-education cell but who did not have a child under age 13. This allows us to compare parents of young children with otherwise similar individuals. We use the same methodology for labor force participation. Because we are aiming to quantify the share of aggregate employment and labor force participation declines, we use all individuals age 16 and up in our calculations, consistent with the official statistics reported by the Bureau of Labor Statistics. Our baseline analysis does not condition on prime-age status.

Table 1 reports the results of this baseline counterfactual calculation. This calculation implies that the effect of any excess impact of the pandemic on parents (overall) with young children can explain none of the decline in aggregate employment rates. In fact, this calculation implies there would have been even more job loss if parents of young children experienced the 
same employment decline as similar adults without a young child, on account of fathers with young children experiencing relatively less employment loss than other men. Looking at both mothers and fathers combined, the data indicate that excess decline in employment among parents of young children can explain negative 3 percent of the aggregate employment-topopulation decline.

When we do the counterfactual calculation only for women, we find that assigning mothers with young children the same percent change in employment as women without young children who are similar in terms of age category and four-year-college-degree status would result in a 0.04 percentage point increase in the aggregate employment-to-population ratio. That can explain 1 percent of the total percentage point decline $(=0.04 / 3.60){ }^{7}$

Our results are similar when considering the labor force participation rate. Assigning the percent change in the labor force participation rate of parents with young children to adults without young children in the same sex-age-education category would have lowered the overall labor force participation rate by an additional 0.03 percentage point, or 2 percent of the actual 1.95 percentage point decline. Conducting the counterfactual for women with young children alone would have raised the labor force participation rate by 0.06 percentage point, offsetting 3 percent of the aggregate decline. ${ }^{8}$

\footnotetext{
${ }^{7}$ Appendix table A1 reports employment changes (in percent terms) for women in various age groups, separately for those with and without a four-year college degree. The point of this table is to simply show more comparisons than are shown in figure 1 and illustrate the extent to which employment declines differ across these dimensions. For instance, among women age 25-39 without a four-year college degree, employment-to-population fell by 9.8 percent among those without a child under 13 and 9.4 percent among those with a child under 13; among women age 25-39 with a four-year college degree, employment-to-population fell by 3.4 percent among those with no child under 13 and 4.5 percent among those with a child under 13. We report percent changes because groups have different baseline employment rates. The table also reports shares of the separate groups in the total workforce. ${ }^{8}$ Lofton, Petrosky-Nadeau, and Seitelman (2021) estimate logit models to predict changes in labor force participation rates between February and November 2020. They find a larger proportional change among prime-age women with a child under 17 (3.0 percent) versus women without (1.8 percent), controlling for age, education, marital status, race/ethnicity, and state. A full reconciliation of their findings and ours is beyond the scope of this paper, but it is instructive to consider what their estimate would imply for the question we investigate: an excess decline in labor force participation of 0.9 percentage points (1.2 percent of original participation rate of 74.1
} 


\section{B. Alternative specifications and robustness checks}

Table 2 presents the results of numerous alternative counterfactual constructions in order to examine the robustness of the baseline counterfactual finding. ${ }^{9}$ We redefine the sets of demographic characteristics used for comparisons to alternately include marital status, income group, race/ethnicity, and industry. ${ }^{10}$ (We do these alternately rather than additively, given shrinking cell sizes.) This allows us to compare parents of young children with adults who are similar along various different dimensions. ${ }^{11}$ When we do this, the simulated change in employment resulting from changing the employment rates of mothers is between -0.01 and 0.04 percentage point and the simulated change in labor force participation rates is between 0.01 and 0.06 percentage point. These specifications similarly yield an upper estimate of 1 percent of the total decline in employment (3.60 percentage points) and 3 percent of the total decline in labor force participation (1.95 percentage points) explained by excess declines among mothers of

percent) among prime-age mothers with a child under 17 (14 percent of the workforce) could account for $0.9 * 0.14 / 1.95=6$ percent of the aggregate reduction in labor force participation we observe between January/February 2020 and January/February 2021.

${ }^{9}$ We also simulated counterfactual employment and labor force participation using an additive percentage point approach, rather than a multiplicative percent approach. This leads to a 0.01 percentage point larger employment decline and thereby implies that excess employment among mothers of children under 13 cannot explain any of the overall decline.

${ }^{10}$ To the extent that mothers with young children tend to work in a different set of industries than women without young children — even conditional on age and college-degree attainment-they would have experienced a differential degree of job loss. Constructing the counterfactual employment numbers adjusting for age, educational attainment, and industry leads to a simulated change in employment of -0.01 percentage point. But, constructing the counterfactual with an adjustment for industry is complicated by the problem of assigning industry to people who are out of work. The CPS asks some out-of-work respondents about the industry of their most recent job. However, this information is missing for 5 percent of unemployed workers and 98 percent of workers not in the labor force in our 2021 sample. Our counterfactual analysis that conditions on industry is thus essentially unable to account for employment loss that results in labor force nonparticipation.

${ }^{11}$ The table also reports the results of simulating changes in employment and labor force participation using only prime-age adults and making no demographic adjustments. For mothers, this would suggest a 0.28 percentage point increase in the employment-to-population rate and 0.31 percentage point increase in labor force participation. We do not consider this a particularly useful approach, since it does not make any demographic adjustments. 
children under 13. If we include fathers in the simulation, overall employment and labor force participation would be unchanged or lower. ${ }^{12}$

Table 3 presents the results of conducting the counterfactual analysis using different definitions of “young children.” We alternately assign parents of children less than age 6 or less than age 18 the employment rates of adults without children under these age thresholds. If we consider the excess impact on mothers with children less than 6 , the share of the aggregate employment decline that can be explained is negative. If we consider the excess impact on mothers with children less than 18, the share that can be explained is less than 1 percent. We conclude from these alternative specifications that our qualitative conclusion is not sensitive to the age threshold used to define parents.

Table 4 reports the results of conducting the counterfactuals using different samples. To the extent that all women-including those without young children-disproportionately experienced caregiving burdens that reduced their employment, assigning the employment changes of women without young children to women with young children might still incorporate caregiving burdens into the simulated effect. To address this concern, we use a different counterfactual approach that assigns women with young children the change in employment experienced by demographically similar men without young children. As shown in the table, this counterfactual approach implies an increase of 0.08 percentage point in total employment, which could explain 2 percent of the total employment decline.

An alternative counterfactual group would be parents of teenagers on the theory that these are most similar in unobservable characteristics to families with younger children except

\footnotetext{
${ }^{12}$ Results for full-time employment are similarly small and generally indicate that full-time employment would have been slightly lower if parents of young children experienced the same change in full-time employment rates as individuals without young children. Results for hours worked are similar. These results are reported in appendix table A2.
} 
that they would not be affected by school closures and childcare in the same way. Another would be to exclude parents of teenagers and only include adults with no child under 18 as the counterfactual sample in order to capture people who are less likely to have any child-related caregiving responsibilities. It is not clear which of these groups might provide a better counterfactual for parents of young children, since parents of teenagers face some, but not all, of the childcare needs of parents of young children, but they are also more similar to parents of young children on unobservable dimensions. Table 4 reports the results of these two alternative counterfactual constructions. As shown, the main results are generally not sensitive to either of these alternative counterfactual specifications, except in the case of using parents of teens as a counterfactual and including fathers in the counterfactual assignment.

We also tried to find direct evidence for the impacts of school closures. One method was to compare states that had above and below median rates of in-person schooling (according to this tracker) as of early May 2021. States with below median in-person schooling had larger percent reductions in employment rates for almost all groups by sex and educational attainment—whether or not they had young children—consistent with these states having either more serious problems with the virus or a greater level of mandatory or culturally-induced social distancing. The differences between individuals with and without young children were not, however, systematically different in states with below median in-person schooling as shown in figures $3 a$ and $3 b$.

While we do not find that a differential decline in employment for parents is able to explain a meaningful amount of the overall decline in employment as of early 2021, it is possible that this has changed over the course of the pandemic. To investigate this, we conduct the same counterfactual exercise described above, comparing employment status in the second, third, and 
fourth quarters of 2020 with the corresponding quarter in 2019 and the first quarter of 2021 with the first quarter of 2020. Comparing the same quarter in different years allows us to avoid seasonal effects. Table 5 reports the results. Across the various dates used, we find that differential employment changes for parents of young children can explain between -4 percent and 1 percent of the overall decline in the employment rate; differential changes for mothers can explain between -2 percent and 2 percent of the overall decline. The data thus do not indicate that our qualitative conclusion would be different if we looked at employment, say, in the summer or fall of 2020 instead of the winter of 2021. There is one outlier estimate. In the fourth quarter of 2020, we find that disproportionately large declines in labor force participation by parents could account for 0.17 percentage points, or 10 percent of the fall in labor force participation, with most of the effect coming from mothers.

Finally, we conduct this counterfactual analysis for the recessions of 2001 and 20072009, for the sake of comparison. The results are reported in table 6 . The data indicate that the simulated changes in employment that would have occurred in previous recessions if parents of young children experienced similar changes in employment as other adults are similar to those found for the current context. This suggests that there has not been something very different about how the pandemic and associated school and daycare closings have differentially affected the employment and labor force participation rates of parents with young children relative to other workers who have also experienced the adverse impacts of the combination of the pandemic and associated recession. 


\section{Conclusion}

Our examination of data on employment and labor force participation rates among parents with young children and others over the course of the pandemic (from January/February 2020 to January/February 2021) suggests that overall, parents of young children did not leave the workforce substantially more than other comparable individuals. We constructed counterfactual estimates of what employment declines would have been if mothers and fathers with young children experienced the same change in employment as comparable people without young children. These estimates indicate that a negligible share of the overall decline in employment can be attributed to challenges specific to parents, or even mothers specifically, with young children.

While school closures and ongoing childcare challenges have substantially burdened parents and children alike, they do not appear to be a meaningful driver of the slow employment recovery. This means that the factors responsible for the slow employment recovery and depressed labor supply are issues that are not exclusively related to the struggles of working parents, such as the continued concern about the threat of getting COVID-19 at work or expanded unemployment insurance benefits and eligibility.

Crucially, the fact that aggregate job losses do not appear to be explained by excess job losses among mothers with young children (after accounting for other factors like age and education) does not mean that mothers with young children have not been especially burdened over the past year. The fact that these women did not disproportionately retreat from the workforce in substantially larger numbers, while shouldering increased childcare and educational responsibilities for their children, might very well be an indication of excess burden that represents a shortcoming of the safety net established to respond to the COVID-19 crisis. Their 
career trajectories might very well be negatively affected in the coming years, owing to the burdens they took on this past year, in addition to other potential negative effects on mental and physical health. This analysis has focused singularly on employment and labor force participation rates. A full accounting of how the pandemic has affected the economic outcomes of parents and mothers in particular is left for future studies. 


\section{References}

Dingel, Jonathan I., Christina Patterson, and Joseph Vavra. 2020. Childcare Obligations Will Constrain Many Workers When Reopening the US Economy. Working Paper 2020-46 (April). Becker Friedman Institute.

Dorn, Emma, Bryan Hancock, Jimmy Sarakatsannis, and Ellen Viruleg. 2020. COVID-19 and student learning in the United States: The hurt could last a lifetime. McKinsey and Company (June).

Flood, Sarah, Miriam King, Renae Rodgers, Steven Ruggles, and J. Robert Warren. 2020. Integrated Public Use Microdata Series, Current Population Survey: Version 8.0 [dataset]. Minneapolis, MN: IPUMS. https://doi.org/10.18128/D030.V8.0.

Furman, Jason, and Wilson Powell III. 2021.The US labor market is running hot...or not? Realtime Economic Issues Watch blog, May 7. Washington: Peterson Institute for International Economics. https://www.piie.com/blogs/realtime-economic-issues-watch/us-labormarket-running-hotor-not.

Heggeness, Misty L. 2020. Estimating the immediate impact of the COVID-19 shock on parental attachment to the labor market and the double bind of mothers. Review of Economics of the Household 18, no. 4: 1053-1078.

Ip, Greg. 2021. The Job Market Is Tighter Than You Think. Wall Street Journal, April 21. https://www.wsj.com/articles/the-job-market-is-tighter-than-you-think-11619006400.

Lee, Shawna J., Kaitlin P. Ward, Olivia D. Chang, and Kasey M. Downing. 2021. Parenting activities and the transition to home-based education during the COVID-19 pandemic. Children and Youth Services Review 122 (March).

Lofton, Olivia, Nicolas Petrosky-Nadeau, and Lily Seitelman. 2021. Parents in a Pandemic Labor Market. Federal Reserve Bank of San Francisco Working Paper 2021-04 (February).

Peterson, Paul. 2020.The Price Students Pay When Schools Are Closed. Education Next (July).

Strain, Michael. 2021. The Jobs Boom Is Real Despite Disappointing April. Bloomberg Opinion, May 7. https://www.bloomberg.com/opinion/articles/2021-05-07/april-jobs-report-is-abig-disappointment-what-happened. 
Figure 1: Percent change in employment-to-population rate between January/February 2020 and January/February 2021

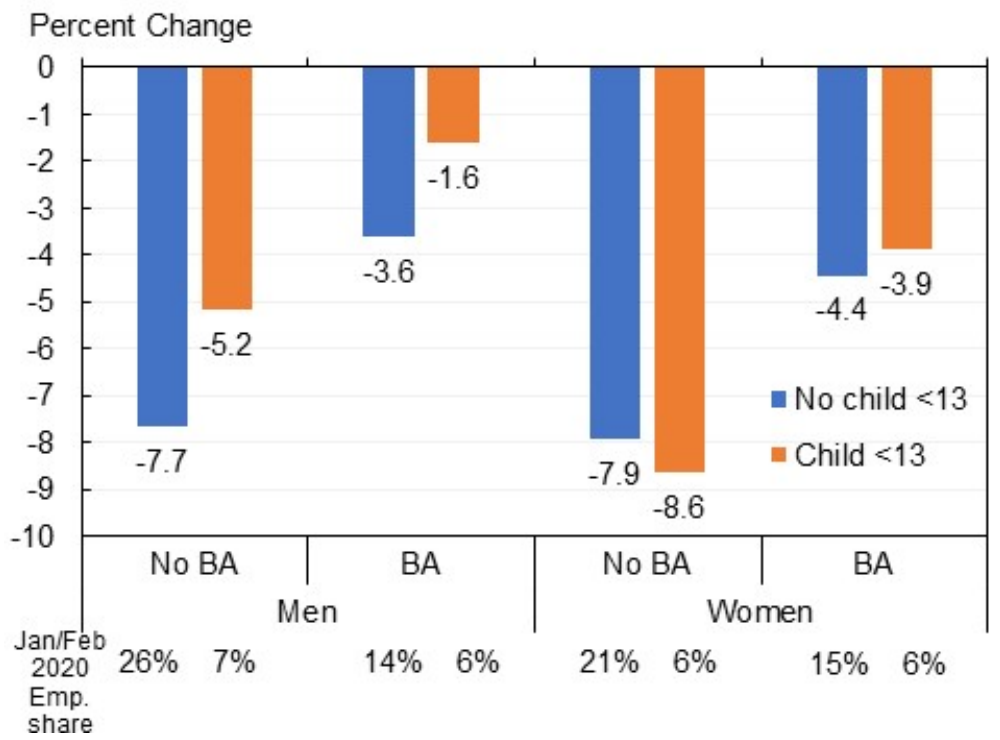

Note: Child refers to own child in the household, including adopted children and stepchildren. Percent of employed population as of January and February 2020.

Sources: Flood et al. (2020); authors' calculations. 
Figure 2: Percentage point change in employment-to-population rate between January/February 2020 and January/February 2021

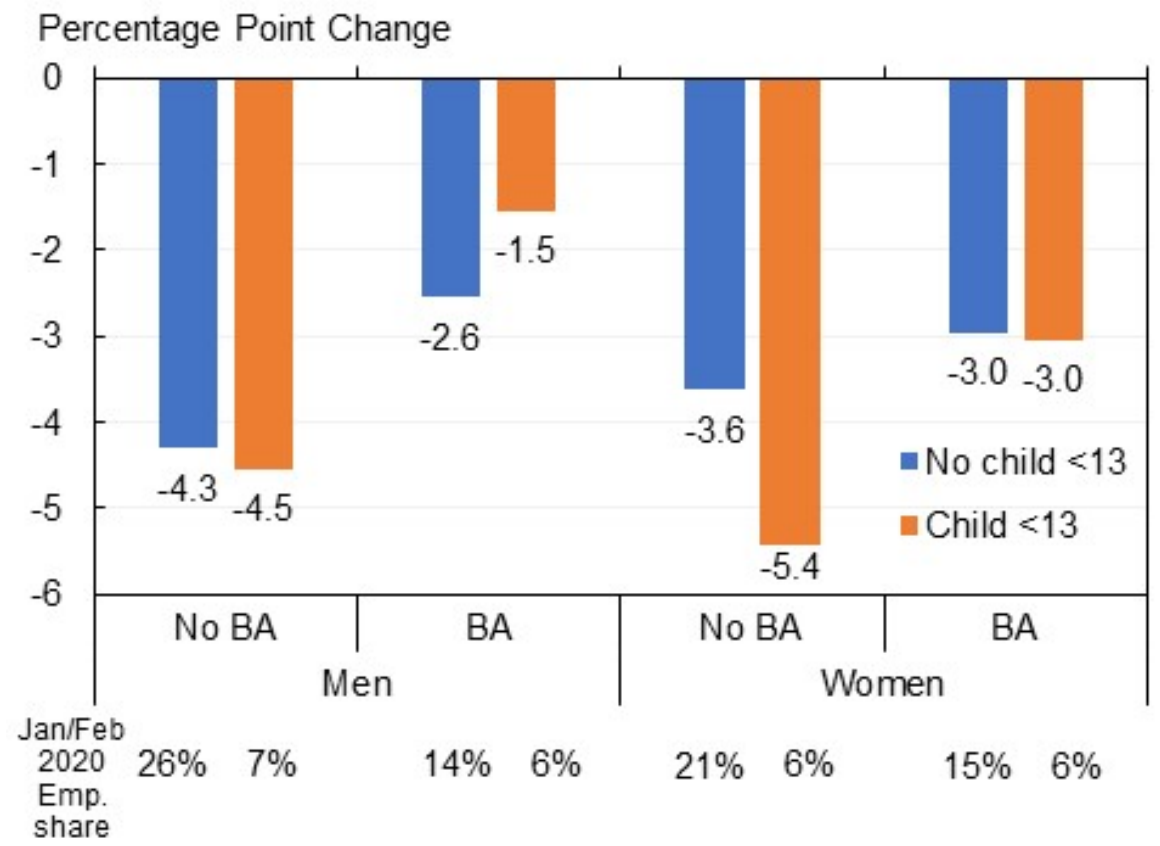

Note: Child refers to own child in the household, including adopted children and stepchildren. Percent of employed population as of January and February 2020.

Sources: Flood et al. (2020); authors' calculations. 
Figure 3a: Percent change in employment-to-population rate, between January/February 2020 and January/February 2021, for states with below median in-person schooling

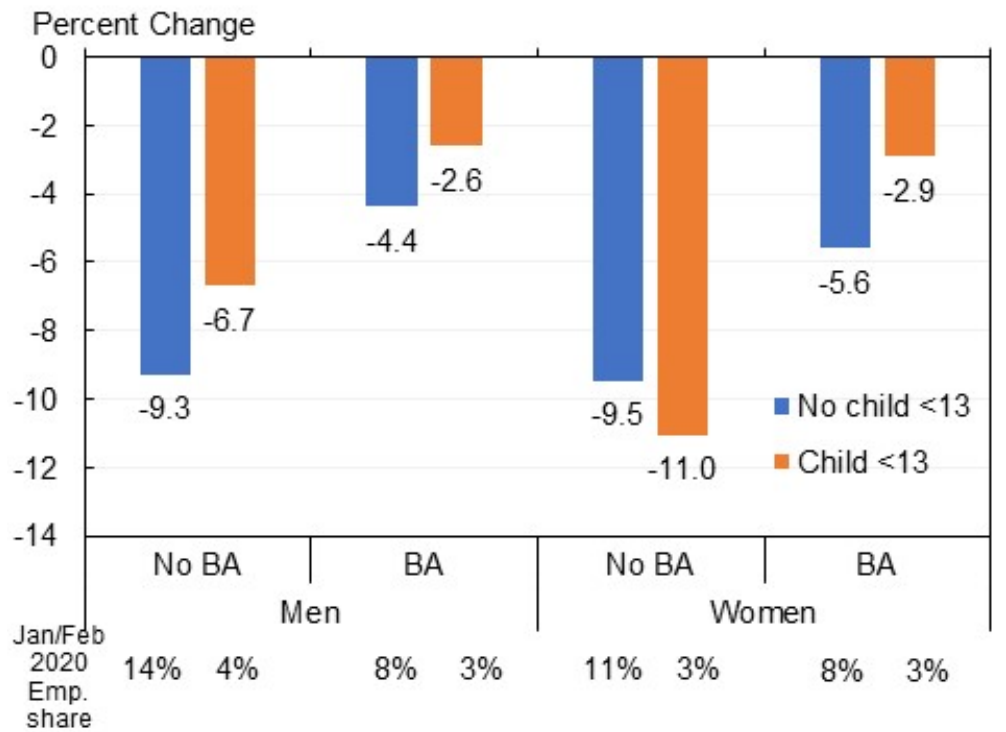

Note: Child refers to own child in the household, including adopted children and stepchildren. Percent of national employed population in states with below median in-person school as of January and February 2020.

Sources: Flood et al. (2020); Burbio; authors' calculations.

Figure 3b: Percentage point change in employment-to-population rate, January/February 2020 and January/February 2021, for states with below median in-person schooling

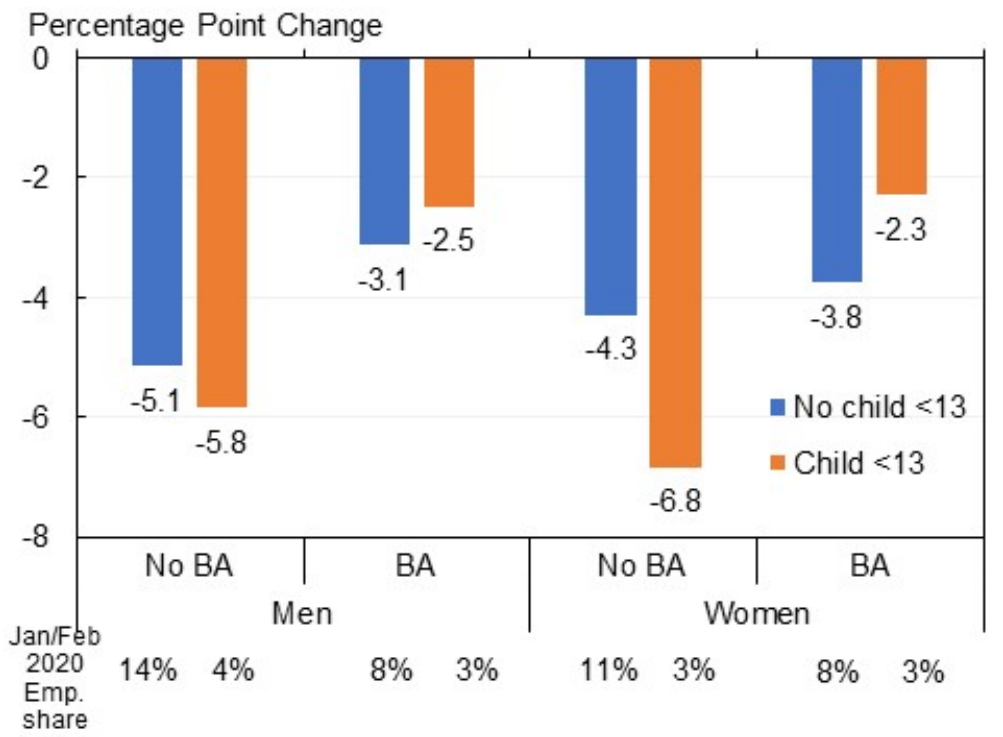

Note: Child refers to own child in the household, including adopted children and stepchildren. Percent of national employed population in states with below median in-person schooling as of January and February 2020.

Sources: Flood et al. (2020); Burbio; authors' calculations. 
Table 1. Change in employment and labor force participation rates, observed and simulated under counterfactual scenario assuming no disproportionate effect on adults with children under age 13, between January/February 2020 and January/ February 2021

\section{Employment-to- $\quad$ Labor Force \\ Population Rate Participation Rate}

\begin{tabular}{lll}
\hline \hline Actual decline in outcome (percent) & & \\
Women & -6.2 & -3.5 \\
Men & -5.6 & -2.7 \\
Total & -5.9 & -3.1
\end{tabular}

Percentage point decline in outcome, total

Difference from actual outcome under baseline counterfactual (p.p.)

$\begin{array}{lcc}\text { Women } & 0.04 & 0.06 \\ \text { Men } & -0.14 & -0.09 \\ \text { Total } & -0.11 & -0.03\end{array}$

Percent of decline explained by differential outcomes of adults with young children

\begin{tabular}{lcc} 
Women & $1 \%$ & $3 \%$ \\
Men & $-4 \%$ & $-5 \%$ \\
Total & $-3 \%$ & $-2 \%$ \\
\hline
\end{tabular}

p.p. = percentage point

Notes: Under the baseline counterfactual, individuals with a child under age 13 are assigned the percent change in the employment rate or labor force participation rate as individuals without a child under age 13 within the same sex, educational attainment (bachelor's degree vs. not), and age (16-24, 25-39, 40-54, 55+) group.

Sources: Flood et al. (2020); authors' calculations. 
Table 2. Simulated difference (in p.p.) from actual outcomes in employment and labor force participation rates, under alternative demographic adjustments, between January/February 2020 and January/February 2021

\begin{tabular}{|c|c|c|c|c|}
\hline & \multicolumn{2}{|c|}{$\begin{array}{l}\text { Employment-to- } \\
\text { Population Rate }\end{array}$} & \multicolumn{2}{|c|}{$\begin{array}{c}\text { Labor Force } \\
\text { Participation Rate }\end{array}$} \\
\hline & Women & Total & Women & Total \\
\hline \multicolumn{5}{|l|}{ Alternative demographic adjustment } \\
\hline No demographic adjustment (naïve counterfactual) & 0.02 & -0.16 & 0.03 & -0.11 \\
\hline Prime-age, no adjustment & 0.28 & 0.02 & 0.31 & 0.16 \\
\hline Adjusting for age & 0.08 & -0.06 & 0.10 & 0.01 \\
\hline Baseline: Adjusting for age and education & 0.04 & -0.11 & 0.06 & -0.03 \\
\hline Adjusting for age, education, and income & 0.03 & -0.10 & 0.05 & -0.04 \\
\hline Adjusting for age, education, and marital status & 0.04 & 0.00 & 0.06 & 0.00 \\
\hline Adjusting for age, education, and race/Hispanic origin & 0.03 & -0.12 & 0.06 & -0.04 \\
\hline Adjusting for age, education, and industry & -0.01 & -0.05 & 0.01 & -0.01 \\
\hline Memo: Percentage point change in outcome & \multicolumn{2}{|c|}{-3.60} & \multicolumn{2}{|c|}{-1.95} \\
\hline Memo: Percentage point change in outcome, prime-age & \multicolumn{2}{|c|}{-4.05} & \multicolumn{2}{|c|}{-1.83} \\
\hline
\end{tabular}

p.p. = percentage point

Sources: Flood et al. (2020); authors' calculations. 
Table 3. Simulated difference (in p.p.) from actual outcomes in employment and labor force participation rates, under alternative child age thresholds, between

January/February 2020 and January/February 2021

\begin{tabular}{|c|c|c|c|c|}
\hline & \multicolumn{2}{|c|}{$\begin{array}{l}\text { Employment-to- } \\
\text { Population Rate }\end{array}$} & \multicolumn{2}{|c|}{$\begin{array}{c}\text { Labor Force } \\
\text { Participation Rate }\end{array}$} \\
\hline & Women & Total & Women & Total \\
\hline \multicolumn{5}{|l|}{ Alternative age thresholds for children } \\
\hline Child under age 6 & -0.03 & -0.11 & -0.03 & -0.10 \\
\hline Child under age 18 & 0.02 & -0.22 & 0.05 & -0.11 \\
\hline Memo: Percentage point change in outcome & \multicolumn{2}{|c|}{-3.60} & \multicolumn{2}{|c|}{-1.95} \\
\hline
\end{tabular}


Table 4 Simulated difference (in p.p.) from actual outcomes in employment and labor force participation rates, under alternative counterfactual approaches, between

January/February 2020 and January/February 2021

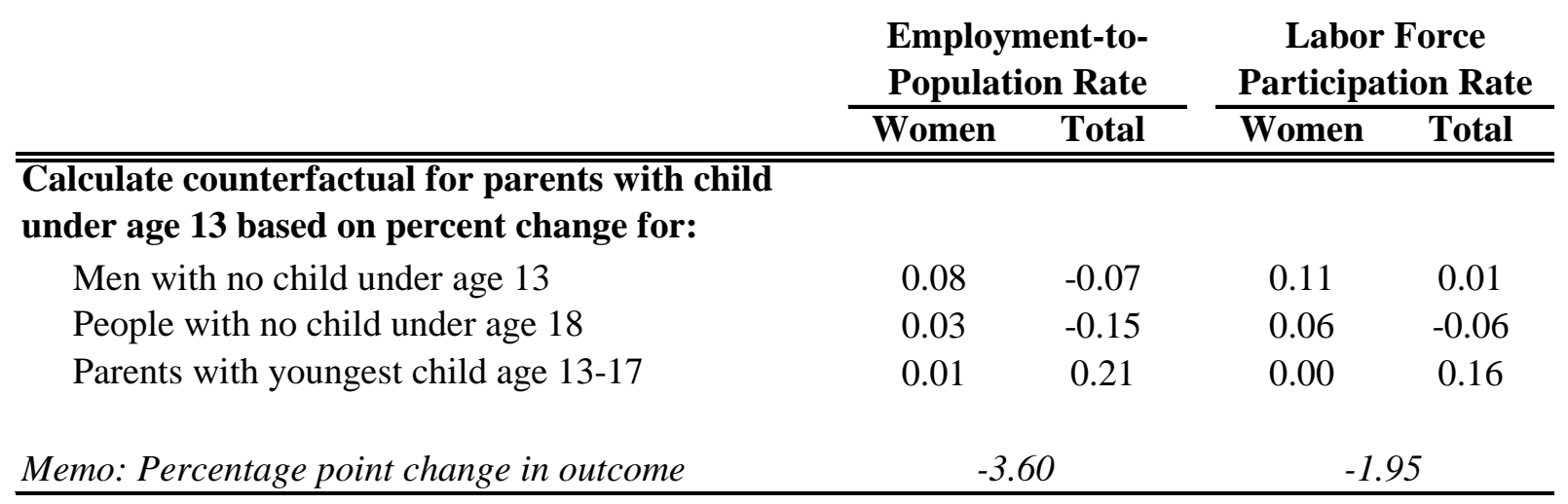

p.p. = percentage point

Note: Counterfactuals adjusted for educational attainment (bachelor's degree vs. not), and age (16-24, 25-39, 40-54, 55+),

consistent with baseline specification.

Sources: Flood et al. (2020); authors' calculations. 
Table 5. Simulated difference (in p.p.) from actual outcomes in employment and labor force participation rates using different dates

\begin{tabular}{|c|c|c|c|c|c|}
\hline & \multirow[t]{2}{*}{$\begin{array}{l}\text { Actual } \\
\text { Change }\end{array}$} & \multicolumn{2}{|c|}{$\begin{array}{l}\text { Difference from Actual } \\
\text { Under Counterfactual } \\
\text { (p.p.) }\end{array}$} & \multicolumn{2}{|c|}{$\begin{array}{l}\text { Percent of Decline } \\
\text { Explained }\end{array}$} \\
\hline & & Women & Total & Women & Total \\
\hline \multicolumn{6}{|c|}{ Employment-to-Population Rate } \\
\hline 2019Q2 to 2020Q2 & -7.77 & -0.06 & -0.24 & $-1 \%$ & $-3 \%$ \\
\hline 2019Q3 to 2020Q3 & -4.80 & -0.07 & -0.18 & $-2 \%$ & $-4 \%$ \\
\hline 2019Q4 to 2020Q4 & -3.60 & 0.07 & 0.02 & $2 \%$ & $1 \%$ \\
\hline 2020Q1 to 2021Q1 & -3.10 & 0.06 & -0.07 & $2 \%$ & $-2 \%$ \\
\hline \multicolumn{6}{|c|}{ Labor Force Participation Rate } \\
\hline 2019Q2 to 2020Q2 & -2.15 & 0.00 & -0.11 & $0 \%$ & $-5 \%$ \\
\hline 2019Q3 to 2020Q3 & -1.74 & -0.04 & -0.07 & $-2 \%$ & $-4 \%$ \\
\hline 2019Q4 to 2020Q4 & -1.75 & 0.13 & 0.17 & $8 \%$ & $10 \%$ \\
\hline 2020Q1 to 2021Q1 & -1.69 & 0.07 & -0.01 & $4 \%$ & $-1 \%$ \\
\hline
\end{tabular}

p.p. = percentage point

Note: Counterfactuals adjusted for educational attainment (bachelor's degree vs. not), and age (16-24, 25-39, 40-54, 55+), consistent with baseline specification.

Sources: Flood et al. (2020); authors' calculations. 
Table 6. Simulated difference (in p.p.) from actual outcomes in employment and labor force participation rates in prior recessions

\begin{tabular}{|c|c|c|c|c|c|}
\hline & \multirow[t]{2}{*}{$\begin{array}{l}\text { Actual } \\
\text { Change }\end{array}$} & \multicolumn{2}{|c|}{$\begin{array}{l}\text { Difference from Actual } \\
\text { Under Counterfactual } \\
\text { (p.p.) }\end{array}$} & \multicolumn{2}{|c|}{$\begin{array}{l}\text { Percent of Decline } \\
\text { Explained }\end{array}$} \\
\hline & & Women & Total & Women & Total \\
\hline \multicolumn{6}{|c|}{$\overline{\text { Employment-to-Population Rate }}$} \\
\hline 2000Q4 to 2002Q4 & -1.73 & 0.05 & -0.05 & $3 \%$ & $-3 \%$ \\
\hline 2007Q4 to 2009Q4 & -4.65 & -0.05 & -0.23 & $-1 \%$ & $-5 \%$ \\
\hline \multicolumn{6}{|c|}{ Labor Force Participation Rate } \\
\hline 2000Q4 to 2002Q4 & -0.53 & 0.01 & -0.09 & $2 \%$ & $-17 \%$ \\
\hline 2007Q4 to 2009Q4 & -1.52 & -0.08 & -0.16 & $-5 \%$ & $-11 \%$ \\
\hline
\end{tabular}

p.p. = percentage point

Note: Counterfactuals adjusted for educational attainment (bachelor's degree vs. not), and age (16-24, 25-39, 40-54, 55+), consistent with baseline specification.

Sources: Flood et al. (2020); authors' calculations. 


\section{Appendix}

Table A1 Percent Change in Women's Employment-to-Population Rates between January/February 2020 and January/February 2021

\begin{tabular}{lccccc} 
Age group & \multicolumn{2}{c}{$\begin{array}{c}\text { No bachelor's degree } \\
\text { No child }<\mathbf{1 3}\end{array}$} & $\begin{array}{c}\text { Bachelor's degree or higher } \\
\text { Child }<\mathbf{1 3}\end{array}$ & $\begin{array}{c}\text { No child }<\mathbf{1 3} \\
\text { Child }<\mathbf{1 3}\end{array}$ & Total \\
\hline \hline \multirow{2}{*}{$\mathbf{1 6 - 2 4}$} & $-6.0 \%$ & $1.8 \%$ & $-6.2 \%$ & $3.9 \%$ & $-5.8 \%$ \\
& $(4 \%)$ & $(0 \%)$ & $(1 \%)$ & $(0 \%)$ & $(6 \%)$ \\
\multirow{2}{*}{$\mathbf{2 5 - 3 9}$} & $-9.8 \%$ & $-9.4 \%$ & $-3.4 \%$ & $-4.5 \%$ & $-6.2 \%$ \\
& $(4 \%)$ & $(4 \%)$ & $(5 \%)$ & $(3 \%)$ & $(16 \%)$ \\
\multirow{4}{*}{$\mathbf{4 0 - 5 4}$} & $-5.7 \%$ & $-10.5 \%$ & $-2.5 \%$ & $-3.2 \%$ & $-4.6 \%$ \\
& $(6 \%)$ & $(2 \%)$ & $(5 \%)$ & $(2 \%)$ & $(14 \%)$ \\
\multirow{2}{*}{$5 \mathbf{5}+$} & $-9.3 \%$ & $4.8 \%$ & $-6.9 \%$ & $-7.5 \%$ & $-7.8 \%$ \\
& $(7 \%)$ & $(0 \%)$ & $(4 \%)$ & $(0 \%)$ & $(11 \%)$ \\
\multirow{2}{*}{ Prime-age } & $-7.3 \%$ & $-9.7 \%$ & $-2.9 \%$ & $-3.9 \%$ & $-5.4 \%$ \\
& $(10 \%)$ & $(6 \%)$ & $(9 \%)$ & $(5 \%)$ & $(30 \%)$ \\
\multirow{2}{*}{ Total } & $-7.9 \%$ & $-8.6 \%$ & $-4.4 \%$ & $-3.9 \%$ & $-6.2 \%$ \\
& $(21 \%)$ & $(6 \%)$ & $(15 \%)$ & $(6 \%)$ & $(47 \%)$ \\
\hline
\end{tabular}

Note: Child refers to own child in the household, including adopted children and stepchildren. Numbers in parentheses report the share of the group in total employment as of January/February 2020.

Sources: Flood et al. (2020); authors' calculations. 
Table A2 Simulated difference from actual outcomes in full-time employment rate (in p.p.) and hours worked per person (in hours per person), under alternative demographic adjustments, between January/February 2020 and January/February 2021

\begin{tabular}{|c|c|c|c|c|}
\hline & \multicolumn{2}{|c|}{$\begin{array}{l}\text { Full-time } \\
\text { Employment-to- } \\
\text { Population Rate }\end{array}$} & \multicolumn{2}{|c|}{$\begin{array}{c}\text { Hours Worked per } \\
\text { Person }\end{array}$} \\
\hline & Women & Total & Women & Total \\
\hline No demographic adjustment (naïve counterfactual) & 0.03 & 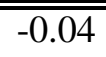 & 0.02 & $\begin{array}{c}-0.03 \\
\end{array}$ \\
\hline Prime-age, no adjustment & 0.07 & -0.08 & 0.08 & 0.00 \\
\hline Adjusting for age & 0.01 & -0.07 & 0.03 & -0.02 \\
\hline Baseline: Adjusting for age and education & -0.02 & -0.12 & 0.00 & -0.04 \\
\hline Memo: Change in outcome & \multicolumn{2}{|c|}{-2.51} & \multicolumn{2}{|c|}{-1.64} \\
\hline Memo: Change in outcome, prime-age & \multicolumn{2}{|c|}{-3.60} & \multicolumn{2}{|c|}{-2.14} \\
\hline
\end{tabular}

p.p. = percentage point

Sources: Flood et al. (2020); authors' calculations. 